International Journal of Innovative Engineering Applications

Journal homepage: https://dergipark.org.tr/ijiea

\title{
INVESTIGATION OF DEEP DRAWABILITY OF RECTANGULAR SHAPED CUPS IN DEEP DRAWING DIES
}

\author{
Cebeli Özek ${ }^{* 1}$ iD, Hayrettin Akkelek ${ }^{1}$ \\ ${ }^{1}$ Fırat Üniversitesi, Teknoloji Fakültesi, Makine Mühendisliği Bölümü, 23119 - Elazığ/Türkiye
}

\begin{abstract}
Original scientific paper

Deep drawing is the process of obtaining three-dimensional containers of certain depths and shapes under pressing forces with the help of drawing molds of sheet materials. In this study, the numerical shaping of rectangular cups in angled deep drawing dies was investigated experimentally and by using the finite element method (FEM). For this purpose, die/blank holder surfaces have $\alpha=0^{\circ}, \alpha=3^{\circ}, \alpha=6^{\circ}, \alpha=9^{\circ}$, $\alpha=12^{\circ}$ and $\alpha=15^{\circ}$ angles in order to facilitate material flow into the die cavity. The punch and die corner radii are taken as $8 \mathrm{~mm}$. St37 steel sheet with a thickness of $0,9 \mathrm{~mm}$ was used as the test material. The experiments were carried out by applying die/blank holder forces of $2500 \mathrm{~N}, 5000 \mathrm{~N}, 7500 \mathrm{~N}$ and $10000 \mathrm{~N}$. The effects of angles and die/blank holder force on limit drawing ratio, wall thickness and the damage of cups were investigated experimentally and numerically, and optimum punch force was determined. Obtained experimental results were compared with ANSYS results. As a result, it has been determined that the increase in die/blank holder surface angles in drawing dies with rectangular geometry with different angles provides a higher limit drawing rate than conventional dies. It has been seen that the experimental results and numerical results are approximate values.
\end{abstract}

Keywords: Rectangular cups, angular deep drawing dies, limit drawing ratio, finite element method, wall thickness.

\section{AÇILI DERIN ÇEKME KALIPLARINDA DIKDÖRTGEN ŞEKILLI KAPLARIN DERIN ÇEKILEBILIRLIĞiNIN ARAŞTIRILMASI}

$\ddot{O}_{z e t}$

Orijinal bilimsel makale

Derin çekme, sac malzemelerin çekme kalıpları yardımıyla press kuvvetleri altında istenilen yükseklik ve şekillerde üç boyutlu kapların üretilmesi işlemidir. Bu çalışmada, dikdörtgen geometriye sahip kapların açılı derin çekme kalıplarında deneysel olarak ve sonlu elemanlar metodu (SEM) ile sayısal olarak şekillendirilmesi araştırılmıştır. Bunun için matris boşluğuna doğru sacın akmasının rahat olması amacıyla Kalıp/pot çemberi yüzeylerine $\alpha=0^{\circ}, \alpha=3^{\circ}, \alpha=6^{\circ}, \alpha=9^{\circ}, \alpha=12^{\circ}$ ve $\alpha=15^{\circ}$ açılar verilmiştir. Istampa ve matris köşe radyüsleri $8 \mathrm{~mm}$ sabit olarak alınmıştır. Deney malzemesi olarak 0,9 mm kalınlığında St37 çelik sac kullanılmıştır. Deneyler, 2500 N, 5000 N, 7500 N ve 10000 $\mathrm{N}$ pot çemberi kuvvetleri uygulanarak yapılmıştır. Açıların ve pot çemberi kuvvetinin limit çekme oranı, cidar kalınlığı ve kap hasarlarına yaptıkları etkileri deneysel ve sayısal olarak incelenmiş ve optimum 1stampa kuvveti belirlenmiştir. Elde edilen deneysel sonuçlar, ANSYS sonuçlarıyla karşılaştırılmıştır. Sonuç olarak, farklı açılara sahip dikdörtgen geometriye sahip çekme kalıplarında matris/pot çemberi yüzey açılarının artmasının klasik kalıplara göre çok iyi limit çekme oranı elde edildiği belirlenmiştir. Deneysel olarak elde edilen sonuçlar ile sayısal sonuçların yaklaşık değerler olduğu gözlenmiştir.

Anahtar Kelimeler: Dikdörtgen kesitli kaplar, açılı derin çekme kalıpları, limit çekme oranı, sonlu elemanlar metodu, cidar kalınlı̆̆ı.

\section{Giriş}

Derin çekme, sac malzemelerin çekme kalıpları yardımıyla press kuvvetleri altında istenilen yükseklik ve şekillerde üç boyutlu kapların üretilmesi işlemidir. Bu işlem, sacdan plakaların kaplara dönüştürülmesinde tercih edilen ve özellikle dairesel, kare, dikdörtgen veya düzgün bir şekli olamayan kapların imalatında önemli avantajlar sunmaktadır. Genelde otomotiv ve uzay sanayisi, ev takım ve eşyaları, mutfak aletleri, paneller ve isıtma soğutma vb. birçok imalat sektöründe geniş olarak yer almaktadır. Derin çekme oranı $(\beta)$, çekilecek malzemenin hasara uğramadan, kopmadan ve ezilmeden yırtılmadan şekillendirilebilen en büyük ilkel sac parça çapının stampa çapına oranı veya sacların şekillendirilebilirlik noktasının bir değeri şeklinde ifade edilmektedir. Derin çekme metoduyla dikdörtgen kapları üretmek silindirik kaplara nazaran çok zor bir iştir. Çünkü sacların dişardan orta 
noktaya doğru itilmesi sırasında kenar noktalarda sacın şekilllendirilmeye karşı verdiği tepki çok daha büyük oluşmakta ve bunun neticesi olarak sacın katlanması ve matris iç kısmında yırtılma/kopma tipinde çatlaklar çok fazla oluşmaktadır. Matrisin biçim ve şekli, sac malzemesinin mekanik özellikleri, ilkel sac plakanın şekli ve boyutu, matris-sac-pot çemberi temasındaki sürtünme ve yağlama koşulları, pot çemberi kuvveti, pot çemberi aralığı gibi etkenler derin çekmenin randımanını direkt etkilemektedir. Dikdörtgen şeklindeki kapların derin şekillendirilmesinde kullanılan sac çeşidi ve matris şekilleri ile çekme oranı $(\beta)$ arasındaki bağlantıyı tespit etmek için pek çok araştırma çalışmaları yapılmıştır.

Derin çekmede şekillendirme sac levhanın kalıp boşluğuna doğru itilmesini sağlayan kabın oluşması ile sonuçlanan zımbanın itme kuvveti vasıtasılya gerçekleştirilir. Bu yöntem yüksek maliyet ve kaynak işlemlerini ortadan kaldırmakta, az sayıda işlemde ve yüksek üretim oranlarında daha iyi kalitede ürünlerin elde edilmesini sağlamaktadır [1]. Derin çekmede büyük elasto-plastik gerilmelerin oluşması ile nihai ürünlerin kalitesini etkileyen çok sayıda parametre mevcuttur. Bu parametreler, geometrik parametreler (zımba yarıçapı, sac kalınlığı, sacın en boy oranı vb.), malzeme parametreleri (elastiklik modülü, akma gerilmesi, plastiklik parametreleri vb.) ve işlem parametreleri (çekme kuvveti, baskı plaka kuvveti, sürtünme katsayıları, sıcaklık vb) gibi parametrelerdir. Bu parametreler birbirleriyle bağlantılı olduğundan ve nihai sonucu etkilediklerinden dolayı parça kalitesi üzerindeki etkilerini ayırt etmek kolay değildir. Bu nedenle, başarılı bir derin çekme için tüm faktörler hakkında geniş bir bilgi birikimi gereklidir [2]. Ana işlem parametrelerinden biri olan belirli bir derin çekme işlemini gerçekleştirmek için gereken kuvvetin maksimum değeri olarak tanımlanan derin çekme kuvveti (DÇK) dir. DÇK, mekanik press kapasitesini tanımlamak, zımbayı tasarlamak, derin çekme işlemini ve gerilmeleri belirlemek için gereklidir. Genellikle silindirik parçaların DÇK'ini tahmini olarak belirlemek için önemli iki ifade vardır. Bu ifadeler, deneysel verilerden elde edilen ampirik ifadeler ve sac levhadan kap oluşturma işleminin elasto-plastik analizinden elde edilen analitik ifadelerdir [3]. Bu ifadeler ampirik ilişkilere dayanan ve gerilmeler hakkında bilgi gerektiren karmaşık denklemlere dayanmaktadır [4, 5]. Dikdörtgen derin çekme işleminin analizi için farklı analitik ifadeler geliştirilmiştir [1,5 ve 6]. Derin çekme işlemlerine olan ihtiyaç artıkça, endüstride yaygın olarak deneme çalışmaları yapılmış ve böylece hatalı sonuçlar veren yöntemlerin kullanımının azalacağına inanılmaktadır. Çalışmalarda genellikle silindirik parçaların DÇK'ni tahmin edecek birkaç denklem mevcut olsa da, bu konuda sınırlı sayıda araştırma çalışması mevcut olup doğru sonuçları tahmin eden ve performansları değerlendirmeye değer bulunmuştur. Silindirik bir parçaya karşıllık gelen deneysel ve sayısal sonuçlar, daha önce bildirilen iki deneysel ifadeden elde edilen sonuçlarla karşılaştırılmıştır $[8,9]$. Dikdörtgen kapların derin çekilmesi durumunda, mevcut DÇK ifadelerinin tahmin performansları ile ilgili henüz net çalışmalar yapılmamıştır.

Kare kapların derin çekilmesinde taslak sac boyutlarının kapların hassasiyeti üzerindeki etkileri araştırmış ve nihai kap hassasiyetine göre taslak sac boyutları belirlenerek bilgisayar kullanım programlarından faydalanarak derin çekme metodunda oluşabilecek kusurlar tespit edilmiştir [10]. Karesel ve silindiriksel ürünlerin şekillendirilmesinde 1stampa şekli ve matris elemanlarının buruşmaya etki eden tesirleri araştırılmış, kare ürünlerin şekillendirilmesinde, buruşmaların meydana gelmesinde rastgele sacın akma miktarının sebep olduğu belirtilmiştir [11]. Kare şeklinde olan parçaların üretilmesinde taslak sac șeklinin etkili olduğu, titanyum plakalar farklı sıcaklıklarda çekilerek taslak sac büyüklüklerinin silindirik sac șeklindeki büyüklüklere haiz olanların daha doğru limit çekme oranları sağladığı görülmüştür [12]. AA5754-O Alüminyum alaşımının kare derin çekme işlemi ile şekillendirilmesinde pot çemberi kuvvetinin $\beta$ üzerinde etkili olduğu, LS-DYNA proğramı kullanılarak elde edilen sonuçların pratik elde edilenlere göre $\% 85$ oranında tutarlı olmaktadır [13]. ETIAL-8 alüminyum malzemenin kare biçimli şekillendirilmesinde pot çemberi aralığının ürün üretim kalitesi ve buruşma üzerinde etkili olduğu, ürün yüzeyi ve buruşma çatlak ve yırtılmalarının meydana gelmemesi için pot çemberi aralığının $1.3 \mathrm{~mm}$ ve $1.7 \mathrm{~mm}$ en uygun değer olmaktadır [14]. Kare kapların üretiminde farklı şekilde bir pot çemberi tasarlanarak pot çemberi üzerine spiral oluklar şekillendirerek üretilen kabın yan kenarlarında cidar kalınlığının değişiminin daha düzgün sağlandığ 1 ve sac hareketiyle akışkan etkileri daha sağlıklı sonuçlar vermektedir [15]. Sacları şekillendirme işleminde, çekme ve burulmaları teorik şekilde hesaplayabilen bir sonlu elemanlar metodu geliştirilerek sonuçların pratik yapılan sonuçlarla uyumlu olduğu tespit edilmiştir [16]. Alüminyum sacların karesel şekillendirilmesinde 1stampa kenar yarıçapları gerilmelerden kaynaklı sertleşmeler üzerinde etkili olduğu, 1stampa yarıçapının düşük tutulması halinde $\beta$ 'nın düştüğü1, fazla alınması halinde ise üretilmiş olan ürünlerdeki çatlak ve yırtılmaların kayda değer oranda düştüğü ve dolayısıyla $\beta$ artmaktadır [17]. Kare biçimli ürünlerin şekillendirilerek üretilmesinde matris büyüklüklerinin (stampa ve taslak parça biçimi, pot çemberi malzemesi ve 1stampa akışkan özelliği) ürün üzerinde etkili olduğu ve bu durumda yırtılmaya sebep olan kuvvetler tespit edilmiştir [18]. Kare şekilli ürünlerin üretimi sırasında üç değişik boyutta taslak sac kullanılarak, nihahi şekillendirmenin daire şekilli taslak elemanda gerçekleştiği kayıt edilmiştir [19]. Galvaniz kaplanmış çeliklerin kare derin çekilmesinde elde edilen ürünlerde oluşan küçülme, bozulma ve alt-üst limit çekme oranları, gerilme yı̆̆ılmaları, hasar şekillerinin 1stampa hızından kaynaklı kuvvetler olduğu görülmüştür [20]. Eşdeğer çap kavramını kullanarak dikdörtgen parçalarda derin çekme kuvveti ile silindirik kaplardaki derin çekme kuvveti için hesaplanan ifadelerin literatürdeki değerler ile uyumlu olduğu ifade edilmiştir [21]. Çelik sac malzemelerde incelme ve kırışıklıkları önlemek için derin çekme işleminde, baskı plakası, kalıp boşluğu, zımba kuvveti, kuru/yağlama gibi farklı derin çekme parametrelerinin etkisi sayısal ve deneysel olarak araştırılmış, dikkate alınan işlem parametreleri için, $2 \mathrm{~mm}$ kalıp boşluğunda, kuru ve yağlamalı 100 kN kuvvet için 1 $\mathrm{mm}$ ve 0,8 mm'lik kalıp boşluğunda daha iyi sonuçlar verdiği gözlemleniştir [22]. Dikdörtgen kaplarda özellikle kaptaki kalınlık değişimlerinin, zımba kuvveti ve geri 
yaylanma kuvveti gibi çeşitli derin çekme parametrelerinde kabın çekilen üst kısmının kalınlığının azaldığı, zımba kuvveti ve baskı plakası kuvvetinin artması ile arttığı, geri yaylanma üzerindeki baskı plakası kuvvetinin etkisinin az olduğunu tespit edilmiştir [23]. AA6014 alüminyum alaşımı malzeme kullanılarak malzemenin kuru derin çekilmesi sayısal ve deneysel olarak analiz etmiş ve sürtünme kuvveti ve sürtünme katsayısı arasında doğrusal bir ilişki olduğu görülmüştür [24]. Derin çekme işlemi sonucunda baskı plakası kuvveti ve sürtünme kuvvetinin çekme oranı üzerindeki etkileri incelemiş, baskı plakası kuvvetinin önemli bir faktör olduğu, kabın ağız kısımlarında gerilme yoğunluğunun baskı plakası kuvvetinden etkilendiği ve sürtünme kuvvetinin, kalınlık dağılımı ve malzemenin yüzey kalitesine bağlı olduğu sonucuna varılmıştır [25]. Yukardaki çalışmalar incelendiğinde, çeşitli saclardan çekme metoduyla dikdörtgen kesitli kapların elde edilmesinde, taslak sac şeklinin, pot çemberi kuvvetleri ve 1stampa yarıçapı gibi pekçok şekillendirme faktörlerinin limit çekme oranı $(\beta)$ na tesirlerinin pratik şekilde çalışıldığı açık olarak mevcuttur. Bu çalışma, dikdörtgen kapların derin çekilmesinde limit çekme oranını (LÇO) tespit etmek amacıyla yapılmıştır. Çalışmada, St37 sacının dikdörtgen şekillendirilmesinde çeşitli şekillendirme faktörlerinin başka kalıp/pot çemberi açısının $(\alpha)$ LÇO $(\beta)$, sstampa kuvveti ve ürün cidar kesiti değişimine etkileri pratik olarak ve Sonlu Elemanlar Metodu (SEM) ile araştırılmıştır.

\section{Deneysel Çalışmalar}

\subsection{Materyal ve Metod}

Bu çalışma ile pot çemberi kuvvetinin ve matris şekil boyutlarının şekillendirme işlemine tesirlerinin araştırılması hedeflenmektedir. Şekillendirilebilme işlemini gerçekleştirebilmek amacıyla çalışmalar matris ve pot çemberi plakası yüzeylerine $0^{\circ}, 3^{\circ}, 6^{\circ}, 9^{\circ}, 12^{\circ}$ ve $15^{\circ}$ açılar verilerek yapılmıştır. Zımba ve kalıp köşe radyüsleri $8 \mathrm{~mm}$ sabit olarak alınmıştır. Deney numuneleri 50x70 mm dikdörtgen boyutlarından başlanarak $2,5 \mathrm{~mm}$ artırılmak süretiyle maksimum 70x90 mm ölçülerinde gelişigüzel kesilmiş ve toplam 160 deney yapılmıştır. Pot çemberi kuvvetleri (PÇK) ise 2,5 kN, 5,0 kN, 7,5 ve 10,0 kN olarak uygulanmıştır. Akışkan olarak özgül ağırlığg 15 ${ }^{\circ}$ C'de $883 \mathrm{~kg} / \mathrm{m}^{3}$ olan Shell Tellus 68 numara yağ kullanılmıştır. Deneylerin yapıldığı deney düzeneğinin şematik resmi Şekil 1'de, çalışmadaki kalıbın boyutları ve teknik resmi ise Şekil 2'de verilmiştir.

Deney çalışmaları $600 \cdot 10^{3} \mathrm{kN}$ 'luk tek tesirli bir hidrolik press makinasında uygulanmıştır. Istampa hızı 4 $\mathrm{mm} / \mathrm{sn}$ sabit olarak tutulmuştur. Çekme esnasında 1stampaya gelen kuvvetlerin tespit edilebilmesi amaciyla CAS LS-20T kapasitesi $200 \cdot 10^{3} \mathrm{kN}$ olan ve $\pm 2 \mathrm{~kg}$ hassasiyetli tek yönlü kuvvet ölçme özelliğine sahip bir dinamometre kullanılmıştır. Istampa kuvvetleri $10^{-1}$ saniye sürelerde tespit edilmiştir.

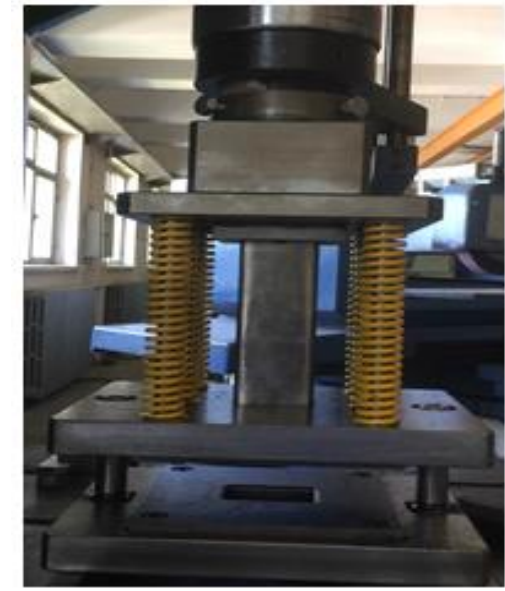

Şekil 1. Deney seti ve sistemi

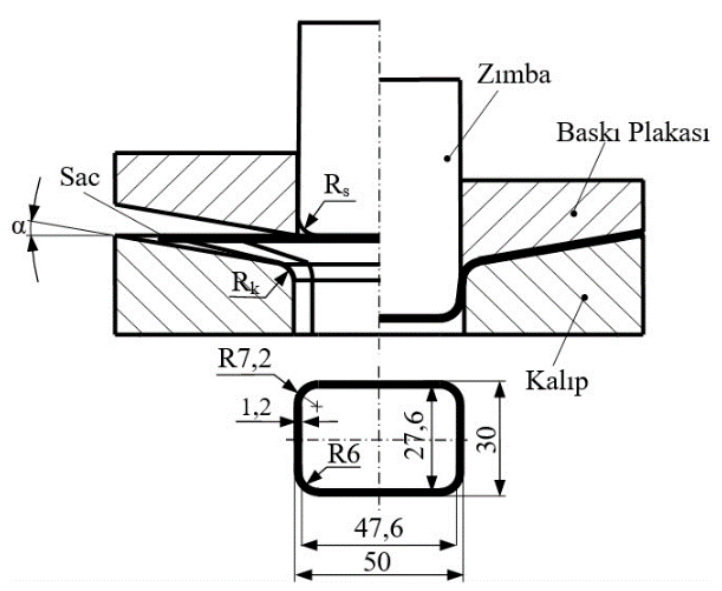

Şekil 2. Deneylerde kullanılan matris ve istampa geometrisi

Deney malzemesi olarak 0,9 mm kalınlığındaki St37 çekme sacı kullanılmış, malzemenin mekanik özelliklerini belirlemek amaciyla SHIMADZU marka $5 \cdot 10^{3} \mathrm{kN}$ kapasitedeki çekme deney makinasında $0^{\circ}, 45^{\circ}$ ve $90^{\circ}$ şeklinde üç çeşit haddeleme yönünde $5 \mathrm{~mm} /$ dak hızla çekme testleri uygulanmıştır. St37 malzemesinin kimyasal bileşimi Tablo 1'de ve mekanik özellikleri de Tablo 2'de mevcuttur. Matris malzemesi olarak soğuk iş takım çeliği (D3) kullanılmıştır. Matris ticari olarak dışarda sanayide üretilerek hazır temin edilmiştir.

Tablo 1. St37 çelik sacının kimyasal özellikleri

\begin{tabular}{cccccc}
\hline $\mathrm{C}$ & $\mathrm{Mn}$ & $\mathrm{P}$ & $\mathrm{S}$ & $\mathrm{Cr}$ & $\mathrm{Mo}$ \\
\hline 0.0442 & 0.242 & 0.109 & 0.0084 & 0.0114 & 0.0114 \\
\hline $\mathrm{Ni}$ & $\mathrm{Cu}$ & $\mathrm{Nb}$ & $\mathrm{Ti}$ & $\mathrm{Sn}$ & $\mathrm{Fe}$ \\
\hline 0.0263 & 0.00451 & 0.00242 & 0.00028 & 0.0866 & 99.466 \\
\hline
\end{tabular}

Tablo 2. St37 çelik sacın mekanik özellikleri

\begin{tabular}{cccc}
\hline $\begin{array}{c}\text { Hadde yönü } \\
\left({ }^{\circ}\right)\end{array}$ & $\begin{array}{c}\text { Akma } \\
\text { dayanımı } \\
\left(\mathrm{N} / \mathrm{mm}^{2}\right)\end{array}$ & $\begin{array}{c}\text { Çekme } \\
\text { dayanımı } \\
\left(\mathrm{N} / \mathrm{mm}^{2}\right)\end{array}$ & $\begin{array}{c}\text { Uzama } \\
(\%)\end{array}$ \\
\hline 0 & 181.53 & 316.83 & 35.99 \\
\hline 45 & 207.34 & 327.79 & 34.08 \\
\hline 90 & 193.46 & 310.53 & 34.22 \\
\hline
\end{tabular}

Çekilecek ilkel parça boyutları, 50x70 mm dikdörtgen ölçülerinde başlayarak 2,5 mm arttırmak suretiyle farklı dikdörtgenler şeklinde kesilerek tam boyutlarda kesilmiş ve bu boyutlardaki saclar derin çekme işlemine tabi tutulmuşlardır. 


\subsection{Eşdeğer Çap Hesabı ve Limit Çekme Oranının Belirlenmesi}

Yapılan çalışmalarda silindirik parçaların iyi bilinen derin çekme teorisini dikdörtgen ve düzensiz parçalara uygulamak için eşdeğer çap kavramı kullanılmaktadır [1, 7, 9]. Parça ilkel eşdeğer çapı $D_{\max }$, Şekil 3 'te gösterildiği gibi, uzunluğu $\mathrm{A}$ ve genişliği $\mathrm{B}$ olan dikdörtgen $\mathrm{A}_{\mathrm{C}}$ alanlı dairesel ve $A_{R}$ alanlı dikdörtgen alanlarının çapı olarak tanımlanmaktadır.

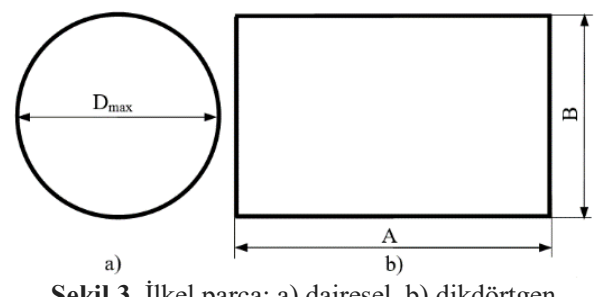

Şekil 3. İlkel parça: a) dairesel, b) dikdörtgen

Genel olarak dikdörtgen derin çekmenin geometrik parametreleri de silindirik derin çekme parametreleri gibi bulunur. Ancak, dikdörtgen derin çekmede bazı ek parametreler gerekmektedir. Dikdörtgen derin çekmenin önemli bir geometrik özelliği, kare için en/boy oranı b/a=1 iken dikdörtgen için en/boy oranı $b / a=1$ değildir. Dolayısıyla limit çekme oranı hesabı için farklı bir yöntem olan eşdeğer çap hesabının yapılması gerekmektedir. Dikdörtgen derin çekme işleminin ana geometrik boyutları Şekil 4'de verilmiştir.

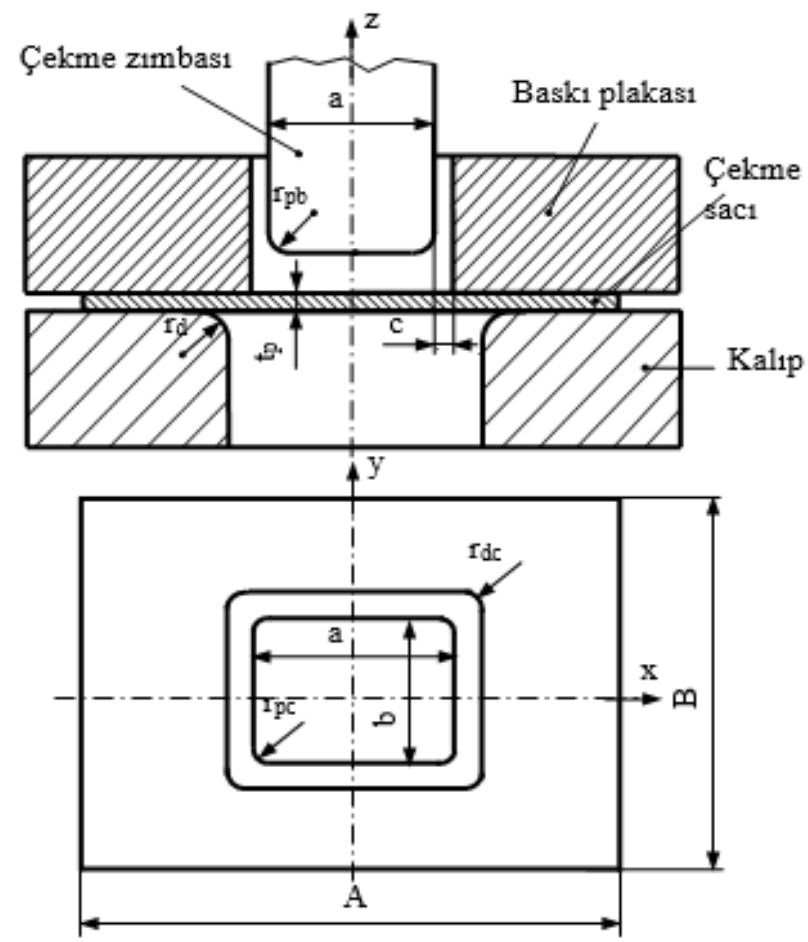

Şekil 4. Dikdörtgen derin çekme işleminin geometrik boyutları

İlkel parçanın en boy oranını göz önüne alarak, eşdeğer çapı belirlemek için "Pisagor eşdeğer çapları" ifadesi kullanılmıştır. Bu yeni ifade Şekil 5 'te gösterildiği gibi eşdeğer çapı tanımlamak için dikdörtgen şeklin karşıt iki köşesi arasındaki mesafeyi dikkate almaktadır. Böylece, yeni eşdeğer çaplar Pisagor Teoremi kullanılarak belirlenmiştir.

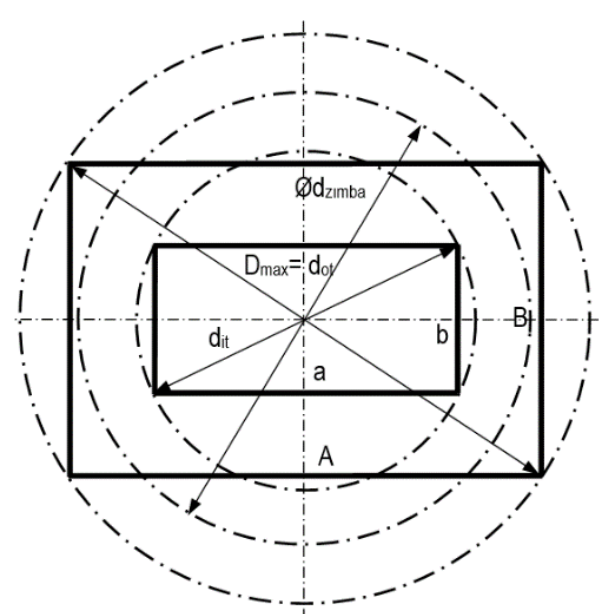

Şekil 5. Dikdörtgen kap için ilkel parça ortalama çapı $\left(D_{\max }\right)$ ve 1 stampa ortalama çapının $\left(\mathrm{d}_{1 \text { stampa }}\right)$ belirlenmesi (Pisagor eşdeğer çapları)

$D_{\max }=\sqrt{A^{2}+B^{2}}$

$\mathrm{d}_{\mathrm{it}}=\sqrt{\mathrm{a}^{2}+\mathrm{b}^{2}}$

$\mathrm{Bu}$ yeni eşdeğer çaplar "Pisagor eşdeğer çapları" olarak adlandırılmaktadır. Dikdörtgen ürünlerin elde edilmesi için limit çekme oranının ( $\beta$ ) belirlenmesinde alınmış olan çaplar Şekil 5'de mevcuttur. Limit çekme oranı, aşağıda verilen 3 denklemine göre tespit edilmiştir.

$\beta=\frac{\emptyset \mathrm{D}_{\max }}{\emptyset \mathrm{d}_{1 \mathrm{stampa}}}$

$\emptyset \mathrm{d}_{\text {stampa }}=\frac{\mathrm{D}_{\max }+\mathrm{d}_{\mathrm{it}}}{2}$

burada, $D_{\max }$ parça ilkel eşdeğer çapı ve $d_{1 \text { stampa }}$ 1stampa eşdeğer çapı olarak alınmaktadır.

\subsection{Cidar Kalınlığının Ölçülmesi}

Gerçekleştirilen denelerin sonucunda üretilmiş olan numunelerdeki kesit incelmelerinin etkisini tespit etmek amacıyla deney numunesi dikkatli bir biçimde kesilerek haddeleme yönünde $5 \mathrm{~mm}$ mesafelerde Izgara olarak bölümlenmişstir. Daha sonra ölçümler, hassasiyeti $10^{-4} \mathrm{~mm}$ olan QLR digit marka dijital bir mikrometre ile belirlenen noktalarda kesit incelmeleri tespit edilmiştir (Şekil 6). Şekil 6'da görüldüğü gibi çekme işleminin sonucunda, üretilmiş olan kapların cidar kalınlıkları dijital mikrometre ile tespit edilmiştir. Bu amaçla, elde edilen kabın yan kenarları $5 \times 5 \mathrm{~mm}^{\prime}$ lik eşit aralıklarla markalanmış ve çakışan noktalardan ölçülmüştür.

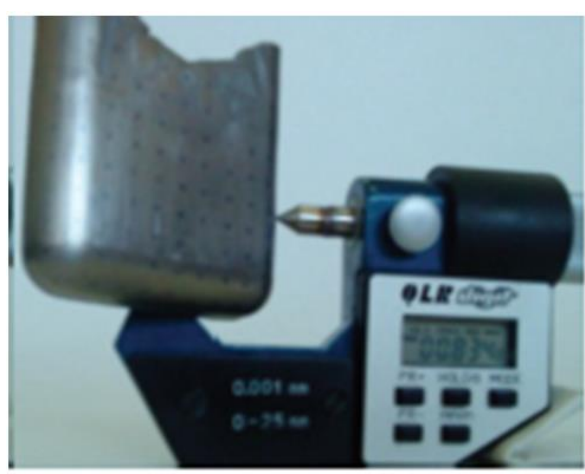

Şekil 6. Cidar kalınlığının ölçülmesi 


\section{Derin Çekme İşleminin Modellenmesi}

Deneylerin yapıldı̆̆ (kalıp boyutları, matris/1stampa yarıçapları, matris/pot çemberi açıları vb.) göz önünde bulundurulduğunda kalıp bileşenlerinin üç boyutlu modelleri SolidWorks2019 hazır programı üzerinden oluşturulmuştur. Oluşturulan kalıp sistemi SolidWorks'de mevcut koordinat noktaları göz önünde bulundurularak ANSYS Workbench hazır programında kalıp şekilleri hazırlanmıştır. Kalıp parçalarının modelinin oluşturulmasından sonra, çözümü yapmak için kullanılmış olan plaka malzeme modeli elde edilmiştir. Elde edilen model için Multilinear Isotropic Hardening malzeme modeli kullanılmıştır. Modelde kullanılan malzemenin özellikleri Tablo 3 'de mevcuttur.

Tablo 3. Modelde kullanılan sac malzeme özellikleri

\begin{tabular}{ll}
\hline Özgül ağırlık $\left(\mathrm{kg} / \mathrm{m}^{3}\right)$ & 7870 \\
\hline Elastisite modülü $\left(\mathrm{kN} / \mathrm{mm}^{2}\right)$ & 196 \\
\hline Poisson oranı & 0,32 \\
\hline Akma gerilmesi $\left(\mathrm{N} / \mathrm{mm}^{2}\right)$ & 200 \\
\hline Çekme gerilmesi $\left(\mathrm{N} / \mathrm{mm}^{2}\right)$ & 315 \\
\hline Bulk modülü $\left(\mathrm{kN} / \mathrm{mm}^{2}\right)$ & 175 \\
\hline Kayma modülü $\left(\mathrm{kN} / \mathrm{mm}^{2}\right)$ & 76,3 \\
\hline
\end{tabular}

A ğ yapılarının elde edilmesi sırasında, pot çemberi, 1stampa ve kalıbın ağ büyüklükleri $10 \mathrm{~mm}$, plaka malzemesinde ise ağ büyüklüğü $3 \mathrm{~mm}$ değerinde verilmiştir. Çalışmada plakadaki plastik deformasyonun tespit edilmesi temel amaç olduğundan kalıp bileşenlerinin ağ sistemi süre kaybını azaltmak için biraz fazla alınmış, ancak sac plakanın plastik deformasyonu sırasında ıstampa ve kalıp yarıçaplarına değme noktalarının çok hassas alınması için yarıçap yüzeylerinde ağ mesafeleri $2 \mathrm{~mm}$ şeklinde verilmiştir (Şekil 7).

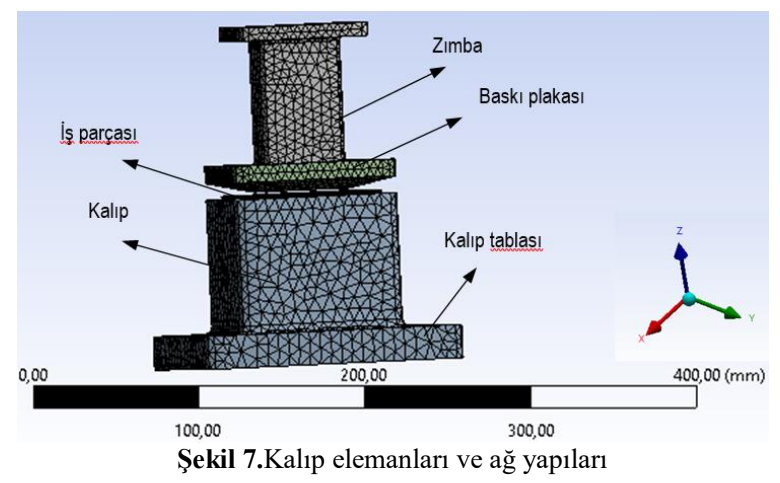

\section{Sonuçlar ve İrdelenmesi}

\subsection{Matris/Pot Çemberi Açısının ( $\alpha$ ) Çekme Oranı ( $\beta$ ) Üzerindeki Etkisi}

Şekil 8'de, çeşitli taslak sac çaplarına göre gerçekleştirilen deneylerden üretilmiş olan kapların hasarları verilmiştir. Şekilden gösterildiği gibi kapların ağız kısımlarına doğru büzülmeler ve ondülasyonlar, alt tabanına doğru ise alt yüzeye enlemesine ve kap boyuna doğru yırtılma ve çatlaklar biçiminde yırtılmalar ve çatlaklar oluştuğu görülmektedir. Taslak sacın çap1 artıkça sacda hasar meydana getirecek 1stampa kuvveti büyümekte ve 1stampa kuvvetinin büyümesi kuvvetin uygulanması sırasında meydana gelen gerginliklerin artmasına neden olmaktadır. Bu yüzden deneysel çalışma anında meydana gelen bu aşırı gerginliklere dayanamayan sac malzemelerde kopmalar, çatlaklar ve yırtılmalar oluşmakta ve şekillendirme işleminde iyi bir sonuç elde edilememektedir [5]. Pot çemberi kuvvetinin (PÇK) fazla alındı ̆̆ zaman çatlaklar temelde numunenin alt kısmında oluşmakta, PÇK'nin az seçildiği zamanda ise kulaklanmaların fazla olma sından numune üst bölgesinde çok fazla büzülmeler oluşmakta, buda kabın ağız kısımlarında çatlakların ve kopmaların meydana gelmesine neden olmaktadır.

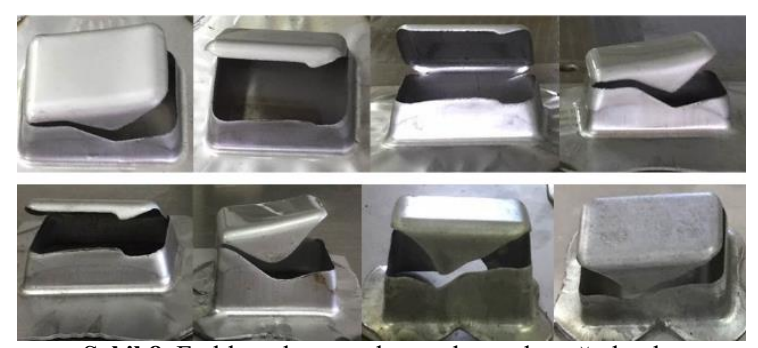

Şekil 8. Farklı çatlama ve kopmaların oluştuğu kaplar

Şekil 9'da, kalıp/pot çemberi açısının değişimine bağlı olarak üretilmiş numuneler görülmektedir. Şekilde verildiği gibi, kalıp/pot çemberi açısının büyümesi ile limit çekme oranı $(\beta)^{\prime}$ da büyümektedir. Bunun nedeni, matris açısının büyük alınması ile sacın matris içerisine hareketinin çok daha rahat olmasından kaynaklanmaktadır. Istampa ile matris boşluğunda çekmeye çalışılan sacın çekme gerilmelerine karşı göstermiş olduğu direnç, matris açısının büyümesi ile düşmektedir [5]. Çekme gerilmelerine etki eden en önemli faktörlerden bir tanesi de kuvvet uygulandığ1 zaman matrisin saca yapmış olduğu baskıdır.

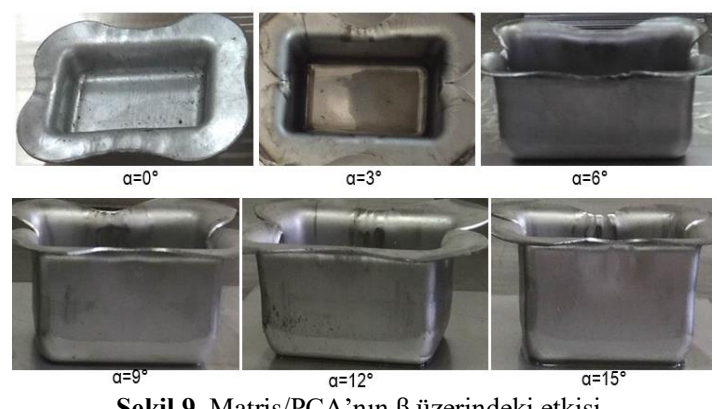

Şekil 9. Matris/PÇA’nın $\beta$ üzerindeki etkisi,

Şekil 10'da, derin çekme işleminde kaydedilen zımba kuvvetlerinin kurs boyuna bağlı olarak değişimi verilmiştir. Görüldüğü gibi matris/pot çemberi açısının her değerinde 1stampa kuvvetinin kap yüksekliğine göre farklılık göstermesi aynı değişimi vermektedir.

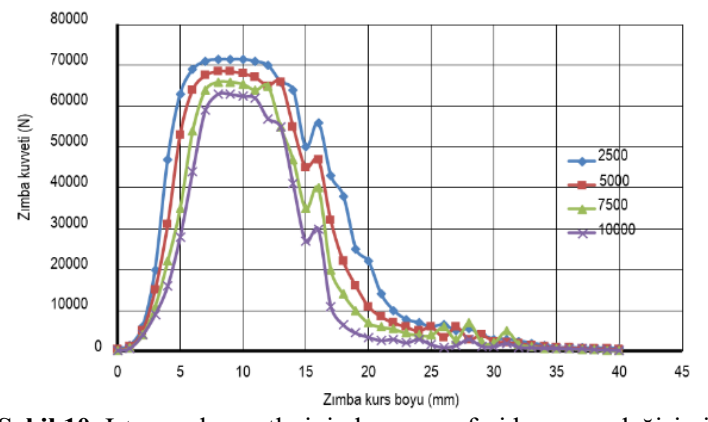

Şekil 10. Istampa kuvvetlerinin kurs mesafesi boyunca değişimi 
Şekil 11'de kap yüksekliklerine göre SEM yöntemiyle çekilmiş olan kaplarda görülen maksimum ve minimum kayma gerilmelerin değişimi ve elde edilen kaplar verilmiştir.
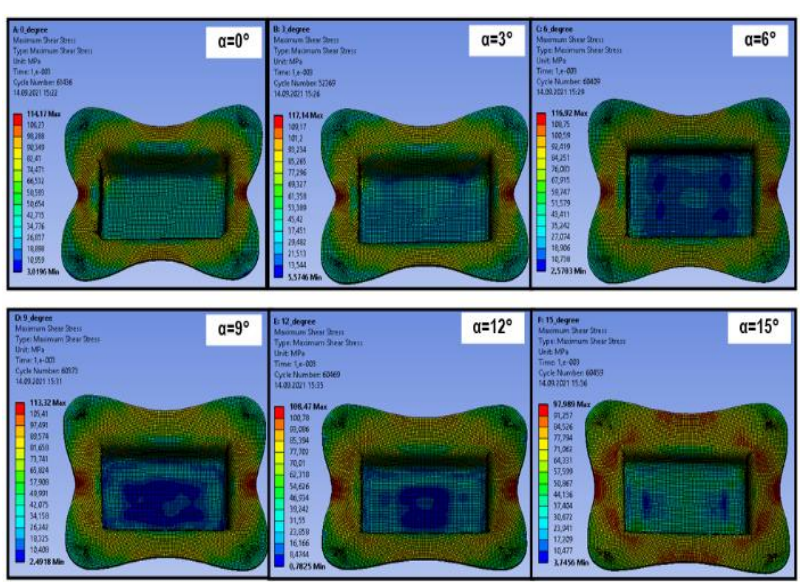

Şekil 11. Matris/pot çemberi açısının değişiminin gerilmeye etkis

Görüldüğü gibi $\alpha=0^{\circ}$ için maksimum kayma gerilmesi $114,17 \mathrm{MPa}$, minimum kayma gerilmesi ise $3,0196 \mathrm{MPa}$ ve $\alpha=15^{\circ}$ için ise maksimum kayma gerilmesi 91,257 $\mathrm{MPa}$, minimum kayma gerilmesi ise 3,7456 $\mathrm{MPa}$ olarak elde edilmiştir. Sırasıyla diğer açılardaki gerilmeler ise $\alpha=3^{\circ}$ için maksimum kayma gerilmesi $117,14 \mathrm{MPa}$, minimum kayma gerilmesi ise 5,5746 $\mathrm{MPa}$, ve $\alpha=6^{\circ}$ için maksimum kayma gerilmesi $116,92 \mathrm{MPa}$, minimum kayma gerilmesi ise $2,5703 \mathrm{MPa}, \alpha=9^{\circ}$ için maksimum kayma gerilmesi $105,41 \mathrm{MPa}$, minimum kayma gerilmesi ise $2,4918 \mathrm{MPa}, \alpha=12^{\circ}$ için maksimum kayma gerilmesi $100,78 \mathrm{MPa}$, minimum kayma gerilmesi ise 0,7825,5703 $\mathrm{MPa}$, olarak elde edilmişlerdir. $\mathrm{Bu}$ gerilmeler, kap yüksekliği ve tespit edilen matris kuvveti değerleri ile değerlendirildiğinde, matris kuvvetlerinin hemen hemen 8 mm'lik hareket mesafesinde doğerusal bir biçimde büyüdüğü, 10-20 mm'lik zımba hareketi boyunca matris kuvvetlerinde ve net oluşan gerilmelerde önemli bir düşüşün olduğu, tahminen $15 \mathrm{~mm}$ zımba hareketinde ise anlık bir büyüme meydana gelmiştir. Bu büyüme, zımba hareket mesafesinin büyümesi ile birlikte matris boşluğuna çekilen sac miktarının da çok olmasıyla değerlendirilebilir. Sac boyutları büyüdükçe, kapta aşırı kalınlaşmalar ve bu nedenle daha büyük zımba kuvvetlerinin uygulanması gerekmektedir.

\subsection{Matris/Pot Çemberi Açısının ( $\alpha$ ) Limit Çekme Oranı ( $\beta$ ) Üzerindeki Etkisi}

Deney sırasında zımba kuvvetinin uygulanması ile sac plakaya pot çemberi kullanılarak istenilen kuvvetin tatbik edilmesi kapta meydana gelebilecek büzülme ve ondulasyonlar engellenerek şekillendirme işlemi başarılı olarak yapılmış olmaktadır. Deneysel çalışmalarda pot çemberi kuvvetinin şekillendirmeye olan etkisini tespit etmek için, pot çemberi kuvvetleri 4 farklı değer olarak uygulanmıştır. Şekil 12'de, kalıp/zımba radyüsü $\mathrm{R}=8 \mathrm{~mm}$ sabit olduğu durumda baskı plakası kuvvetlerine bağlı olarak kalıp/pot çemberi açısının limit çekme oranı $(\beta)$ üzerindeki etkisi görülmektedir. Görüldüğü gibi artan kalıp/pot çemberi açısına bağlı olarak limit çekme oranı artmaktadır. Özellikle PÇK $=2500 \mathrm{~N}$ için $12^{\circ}$ 'den sonra limit çekme oranının azaldığı görülmüştür. Optimum açının $12^{\circ}$ olması gerektiği söylenebilir. PÇK'nin 10000 $\mathrm{N}$ olması halinde ürün alt kısımlarında erken yırtılmalar meydana gelmekte ve limit çekme oranı $(\beta)$ miktarı düşmektedir. PÇK'nin 5000 ve $7500 \mathrm{~N}$ değerlerinde ise $\beta$ 'nın eșit ve diğer PÇK'ne göre daha yüksek olduğu görülmektedir. Dolayısıyla, ideal $\beta$ için, PÇK'nin 5000 ve $7500 \mathrm{~N}$ olmasi gerekmektedir.

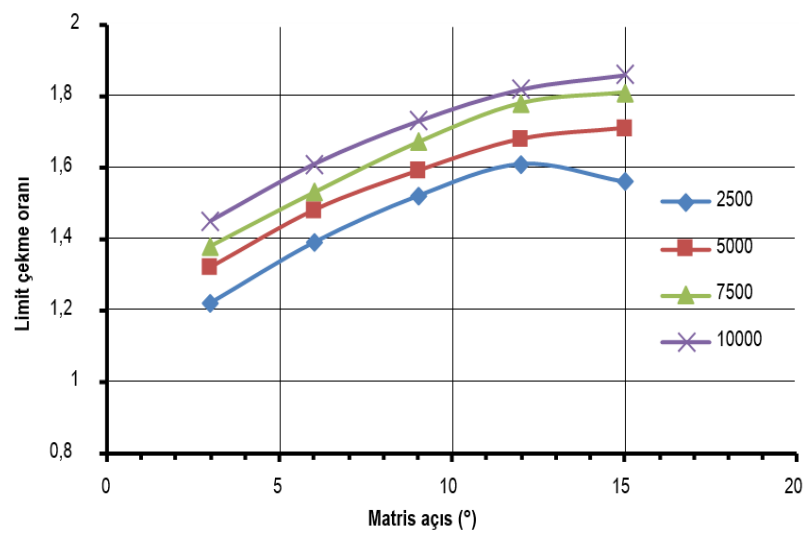

Şekil 12. Pot çemberi kuvvetinin limit çekme oranı $(\beta)$ üzerindeki etkisi

\subsection{Kalıp/Pot Çemberi Açısının (a) Et Kalınlığı Üzerindeki Etkisi}

Şekil 13'de sabit $\mathrm{R}=8 \mathrm{~mm}$ değerinde kap yüksekliğine bağlı olarak kalıp/pot çemberi açısının cidar kalınlığı üzerindeki etkisinin değişimi verilmiştir.

Deneysel çalışmalar sırasında numuneler üzerinde birden fazla farklı türde gerilmeler oluşmaktadır. Bu gerilmeler numunenin kesit kalınlıklarındaki değişimleri direkt olarak etkilemektedir [19]. Bu yüzden deneysel çalışmaların uygulanması sırasında numunelerde oluşabilecek kesit kalınlık değişimlerinin oluşmamasına özen gösterilmelidir. Kapların hassas bir şekilde üretilebilmesi için kaplardaki kesit incelmeleri önlenmelidir. Kaplardaki kesit incelmelerinin değişimi elde edilecek olan ürün kalitesi üzerinde etkili olmaktadır.

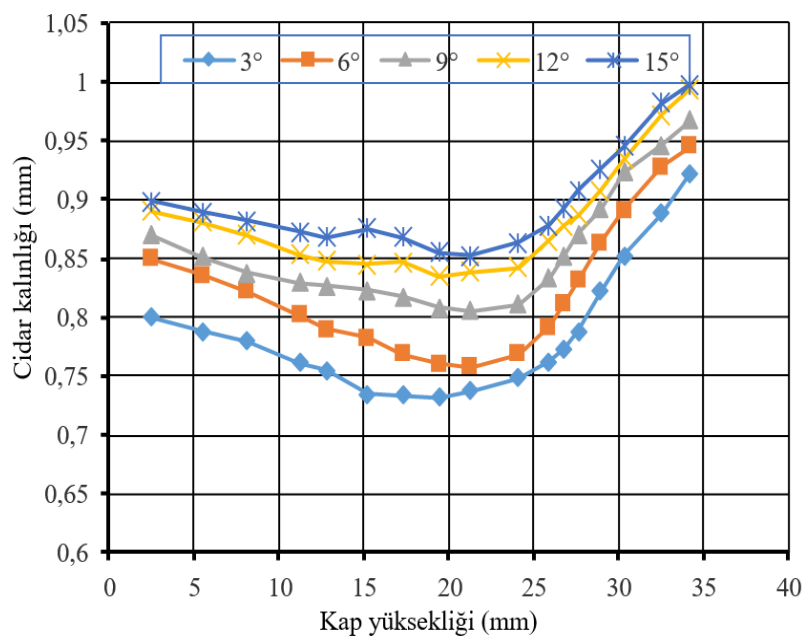

Şekil 13. Kalıp/pot çemberi açısının cidar kalınlığı üzerindeki etkisi

Kesit incelmelerinin önüne geçmek bakımından açının büyük oranda önemi vardır. Ancak kalıp/pot çemberi açısına bağlı olarak kalınlık değişimleri benzer 
eğilim göstermektedir. Kap boyunun 0-15 mm olan aralığında kesit incelmelerinin düştüğü ve 0,75-0,94 mm gibi bir değer aralığında olduğu, sac kalınlığındaki kesit incelme değerinin ortalama \%10 miktarında düştüğü, 15$20 \mathrm{~mm}$ aralığında ise sabit olduğu söylenebilir. 20 mm'den sonra numunenin ağız kısımlarına doğru kaptaki kesit incelmeleri aşamalı bir biçimde yükselmekte ve özellikle $30 \mathrm{~mm}$ 'den itibaren kesit incelmelerindeki farklılık sac plaka kalınlığından daha fazla olduğu görülmüștür. Kalınlıktaki bu fazlalaşma yaklaşık \%24'dür. Kalıp/pot çemberi açısının $(\alpha)$ hemen hemen her değerinde kesit değişimlerinde aynı durum görülmektedir.

\section{Sonuçlar ve Tartışma}

$\mathrm{Bu}$ çalışmada, St37 çeliğinden dikdörtgen kesitli kapların açılı derin çekme kalıplarında şekillendirilmesi esnasında kalıp/pot çebmeri açısı ve pot çemberi kuvvetinin limit çekme oranı $(\beta)$ ve cidar kalınlığ üzerindeki etkileri deneysel ve sayısal olarak araştırılmıştır. Çalışma sonucunda çıkarılan genel sonuçlar aşağıda verilmiştir.

1. Kalıp/pot çemberi açısı $(\alpha)$ arttıkça pot çemberi kuvvetindeki artışın cidar kalınlığı değişimine olan etkisinin azaldığ 1 , bu durumun en fazla deformasyon olayının gerçekleştiği kap üst kısımlarındaki geri esneme miktarının kap alt kısımlarındaki geri esneme miktarından daha düşük olmasından kaynaklandığı ve kalıplama kuvvetini etkileyen en önemli faktörün kalıp/pot çemberi açısı ve kalıp/pot çemberi kuvveti olduğu görülmüştür.

2. Kalıp/pot çemberi açısı $(\alpha)$ değerlerinin artması ile LÇO $(\beta)^{\prime}$ da artmaktadır. St37 derin çekme sacının klasik yöntemle $\left(\alpha=0^{\circ}\right)$ çekilmesinde $\beta=1.20$ iken, kalıp ve pot çemberine açı vermek suretiyle $\left(\alpha=3-15^{\circ}\right) \beta$ değeri, $1.55^{\prime}$ e kadar yükseltilebilmiştir. SEM yöntemi ile elde edilen maksimum $\beta$ değeri ise $\alpha=10^{\circ}$ olduğu şartlarda, 1.61 olarak tespit edilmiştir.

3. PÇK'nin $2500 \mathrm{~N}$ ve $10000 \mathrm{~N}$ alınmaları halinde, elde edilen kaplarda kulaklanmalar, erken yırtılmalar ve çatlaklar meydana gelmektedir. Dolayısıyla limit çekme oranı $(\beta)$ istenilen değerde elde edilememektedir. PÇK'nin 5000 ve $7500 \mathrm{~N}$ alınması sırasında ise daha büyük limit çekme oranı $(\beta)$ ve daha düzenli kaplar elde edilebilmektedir.

4. İlkel parça çapları aynı olan kaplarda kesit kalınlık değişimleri kabın ağız kısımlarında artmakta, taban bölgelerinde ise azalmaktadır. Kabın orta bölgelerinde daha düzenli ve sabit bir değişim göstermektedir. $\alpha=0^{\circ}$ iken minimum kalınlık $0.725 \mathrm{~mm}$ iken, $\alpha$ 'nın $3^{\circ}, 6^{\circ}, 9^{\circ}$, $12^{\circ}$ ve $15^{\circ}$ alınması halinde minimum kesit değişimleri sirasıly $0.720,0.760,0.820,0.840$ ve $0,860 \mathrm{~mm}$ değerleri olarak ölçülmüştür. Matris açısının büyümesi ile kesitlerdeki incelmenin düştüğü tespit edilmiştir.

Bu makale Fırat Üniversitesi Fen Bilimleri Enstitüsü Makine Teknolojileri Programı'nda “Açılı Derin Çekme Kalıplarında Dikdörtgen Şekilli Kapların Ilık Derin Çekilebilirliğinin Araştırılması" adı ile kayıtlı yüksek lisans tezindeki verilerden hazırlanmıştır.

\section{Açıklamalar}

$\mathrm{Bu}$ çalışmada etik kurul onay belgesine gerek yoktur.

\section{Kaynaklar}

[1] Medellín-Castillo, H. I., Garcia-Zugasti, P. D. J., de Lange, D. F., \& Colorado-Alonso, F. J. (2013). Analysis of the allowable deep drawing height of rectangular steel parts. The International Journal of Advanced Manufacturing Technology, 66(1-4), 371-380.

[2] Singh, C. P., \& Agnihotri, G. (2015). Study of deep drawing process parameters: a review. International Journal of Scientific and Research Publications, 5(2), 1-15.

[3] Aarón Rivas-Menchi A. (2015). Análisis del Efecto de Diversos Parámetros en el Desempeño del Proceso de Embutido de Formas Rectangulares. (Master's dissertation, Universidad Autónoma de San Luis Potosí).

[4] Tschaetsch H. (2006). Metal forming practice. New York: Springer.

[5] Daxin, E., Mizuno, T., \& Li, Z. (2008). Stress analysis of rectangular cup drawing. Journal of materials processing technology, 205(1-3), 469-476.

[6] Menchi, A. R., Medellín Castillo, H. I., de Lange, D. F., \& García Zugasti, P. D. J. (2014, November). Influence of geometrical parameters on the maximum deep drawing height of rectangular parts. In ASME International Mechanical Engineering Congress and Exposition (Vol. 46438, p. V02AT02A016). American Society of Mechanical Engineers.

[7] García-Zugasti P, de J. (2005). Proceso de Embutido de Productos Rectangulares de Lámina (Estudio TeóricoPráctico). (Doctoral dissertation, México: Universidad de Guanajuato).

[8] García, C., Celentano, D., Flores, F., Ponthot, J. P., \& Oliva, O. (2006). Numerical modelling and experimental validation of steel deep drawing processes: Part II: Applications. Journal of materials processing technology, 172(3), 461-471.

[9] Groover, M. P. (2020). Fundamentals of modern manufacturing: materials, processes, and systems. John Wiley \& Sons.

[10] Choi, T. H., \& Huh, H. (1999). Sheet metal forming analysis of planar anisotropic materials by a modified membrane finite element method with bending effect. Journal of Materials Processing Technology, 89, 58-64.

[11] Thiruvarudchelvan, S., Travis, F. W., \& Poh, T. K. (1999). On the deep drawing of cups with punch and blank-holding forces proportional to a hydraulic pressure. Journal of Materials Processing Technology, 92, 375-380.

[12] Padmanabhan, R., Oliveira, M. C., Baptista, A. J., Alves, J. L., \& Menezes, L. F. (2009). Blank design for deep drawn parts using parametric NURBS surfaces. Journal of materials processing technology, 209(5), 2402-2411.

[13] Saxena, R. K., \& Dixit, P. M. (2009). Finite element simulation of earing defect in deep drawing. The International Journal of Advanced Manufacturing Technology, 45(3-4), 219.

[14] Yang, T. S. (2008). Finite element analysis of square cup deep drawing of pure titanium metal sheet at elevated temperatures. In Advanced Design and Manufacture to Gain a Competitive Edge (pp. 33-42). Springer, London.

[15] Demirci, H. I., Esner, C., \& Yasar, M. (2008). Effect of the blank holder force on drawing of aluminum alloy square cup: Theoretical and experimental investigation. Journal of materials processing technology, 206(1-3), 152-160.

[16] Gavas, M., \& Izciler, M. A. H. M. U. T. (2007). Effect of blank holder gap on deep drawing of square cups. Materials \& design, 28(5), 1641-1646.

[17] Gavas, M., \& Izciler, M. A. H. M. U. T. (2006). Design and application of blank holder system with spiral spring in deep drawing of square cups. Journal of Materials Processing Technology, 171(2), 274-282. 
[18] Menezes, L. F., \& Teodosiu, C. (2000). Three-dimensional numerical simulation of the deep-drawing process using solid finite elements. Journal of materials processing technology, 97(1-3), 100-106.

[19] Marumo, Y., Saiki, H., \& Mori, T. (1999). Combined effects of strain hardening characteristics and tool geometry on the deep-drawability of square aluminum cups. Journal of Materials Processing Technology, 89, 30-36.

[20] Marumo, Y., \& Saiki, H. (1998). Evaluation of the forming limit of aluminum square cups. Journal of Materials Processing Technology, 80, 427-432.

[21] Rivas-Menchi, A., Medellín-Castillo, H. I., de Lange, D. F., \& García-Zugasti, P. D. J. (2018). Performance evaluation of analytical expressions for cylindrical and rectangular deep drawing force estimation. Journal of Manufacturing Processes, 36, 340-350.
[22] Choudhari, C. S., \& Khasbage, S. S. (2021). Experimental investigation of forming parameters for square cup deep drawing process. Materials Today: Proceedings, 44, 42614267.

[23] Aminzahed, I., Mashhadi, M. M., \& Sereshk, M. R. V. (2017). Investigation of holder pressure and size effects in micro deep drawing of rectangular work pieces driven by piezoelectric actuator. Materials Science and Engineering: C, 71, 685-689.

[24] Tenner, J., Andreas, K., Radius, A., \& Merklein, M. (2017). Numerical and experimental investigation of dry deep drawing of aluminum alloys with conventional and coated tool surfaces. Procedia engineering, 207, 2245-2250.

[25] Dwivedi, R., \& Agnihotri, G. (2017). Study of deep drawing process parameters. Materials Today: Proceedings, 4(2), 820-826. 